(C) 2019 by the Arizona Board of Regents on behalf of the University of Arizona. This is an Open Access article, distributed under the terms of the Creative Commons Attribution licence (http://creativecommons. org/licenses/by/4.0/), which permits unrestricted re-use, distribution, and reproduction in any medium, provided the original work is properly cited.

\title{
RADIOCARBON DATING AT GRONINGEN: NEW AND UPDATED CHEMICAL PRETREATMENT PROCEDURES
}

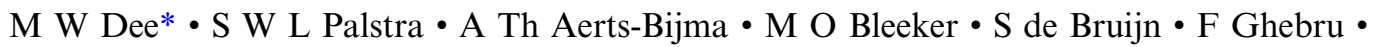 \\ H G Jansen • M Kuitems • D Paul • R R Richie • J J Spriensma • A Scifo • D van Zonneveld • \\ B M A A Verstappen-Dumoulin • P Wietzes-Land $\bullet$ H A J Meijer
}

University of Groningen - Centre for Isotope Research, Faculty of Science and Engineering, Groningen, The Netherlands

\begin{abstract}
The Centre for Isotope Research (CIO) at the University of Groningen has operated a radiocarbon $\left({ }^{14} \mathrm{C}\right)$ dating laboratory for almost 70 years. In 2017, the CIO received a major upgrade, which involved the relocation of the laboratory to new purpose-built premises, and the installation of a MICADAS accelerator mass spectrometer. This period of transition provides an opportunity to update the laboratory's routine procedures. This article addresses all of the processes and quality checks the $\mathrm{CIO}$ has in place for registering, tracking and pretreating samples for radiocarbon dating. Complementary updates relating to radioisotope measurement and uncertainty propagation will be provided in other forthcoming publications. Here, the intention is to relay all the practical information regarding the chemical preparation of samples, and to provide a concise explanation as to why each step is deemed necessary.
\end{abstract}

KEYWORDS: laboratory protocols, pretreatment, radiocarbon AMS dating.

\section{INTRODUCTION}

The Centre for Isotope Research (CIO) hosts the longest-running radiocarbon $\left({ }^{14} \mathrm{C}\right)$ dating unit currently in operation. The first director of the laboratory, Hessel de Vries, was appointed in 1950, and the first ${ }^{14} \mathrm{C}$ dates obtained in 1952 (de Vries and Barendsen 1952). De Vries utilized and made significant developments to the gas proportional counting method of ${ }^{14} \mathrm{C}$ measurement (de Vries and Barendsen 1953). The CIO operated as a conventional facility until the early 1990s, whereupon a 3 MV Tandetron accelerator was obtained from High Voltage Engineering. Over the ensuing decades, the CIO gradually migrated toward making measurements by accelerator mass spectrometry (AMS), and since 2011 has operated exclusively as an AMS laboratory. In 2017, a $200 \mathrm{kV}$ compact accelerator (MICADAS) was purchased from Ionplus AG. The performance of this instrument, as well as updates to routine target preparation and uncertainty propagation, will be discussed in other upcoming articles.

Improvements to the registration and chemical preparation of ${ }^{14} \mathrm{C}$ samples have occurred throughout the entire history of the laboratory. However, a comprehensive overview of such procedures at the CIO has not been produced since Mook and Streurman (1983). This paper discusses the protocols now employed for the registration, tracking and pretreatment of samples submitted for ${ }^{14} \mathrm{C}$ dating. Such samples generally relate to palaeo-environmental, archaeological and forensic studies. All post-bomb ${ }^{14} \mathrm{C}$ research applications on aerosols (see Dusek et al. 2014), atmospheric ${ }^{14} \mathrm{CO}_{2},{ }^{14} \mathrm{C}$ analysis on water samples, and biogenic carbon fraction determination (among others Palstra and Meijer 2014) will not be described in this paper. To cover the array of samples still circumscribed by this overview, each sample material will be dealt with in turn, with specialist approaches discussed separately from routine methods.

The CIO produces $2500-3000{ }^{14} \mathrm{C}$ measurements annually, a number that is expected to increase over the coming years as a result of the growth and advancement of the

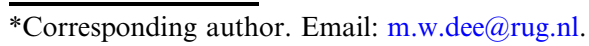




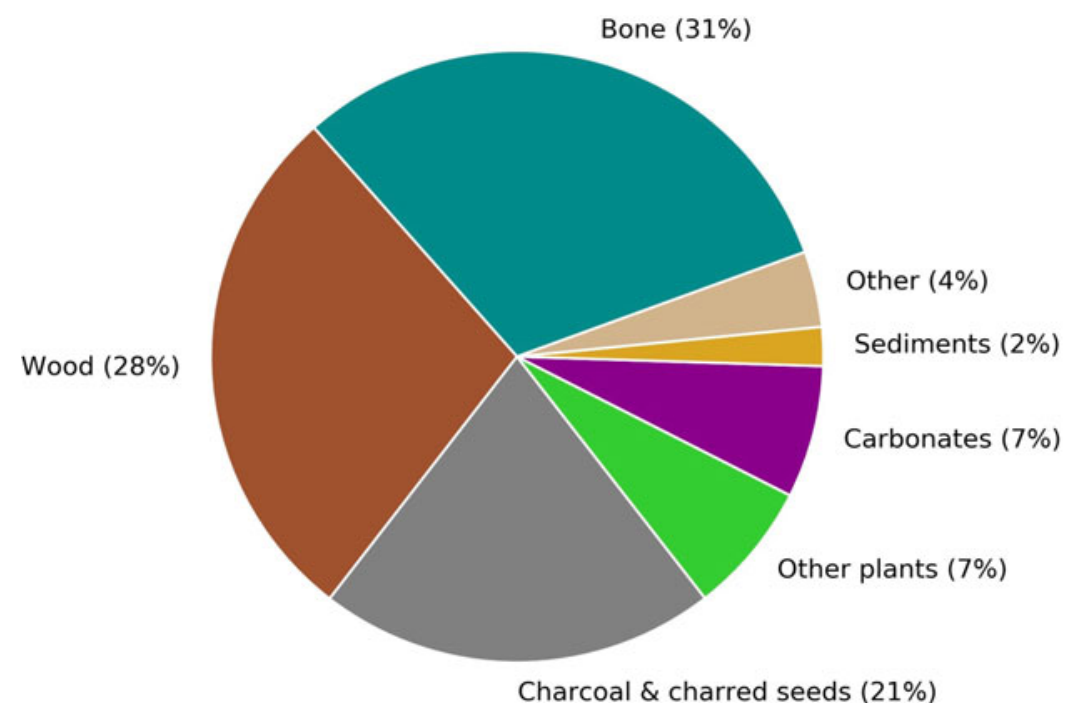

Figure 1 A breakdown by sample type of the materials submitted to Groningen for sample preparation and radiocarbon dating from September 2017 to August 2018. The carbonate group includes both calcined bones and shells.

laboratory. About $80 \%$ of these measurements are obtained for the purposes of ${ }^{14} \mathrm{C}$ dating. Figure 1 gives a breakdown of the main sample types that will be discussed in this paper.

\section{SAMPLE REGISTRATION}

Groningen employs the same template for all sample submissions, which can be found at http:// www.rug.nl/research/centre-for-isotope-research/customers/procedure

Each batch of samples is added to a FileMaker Pro ${ }^{\mathrm{TM}}$ relational database and assigned a unique Project Number. Every individual sample is then allocated an in-house Sample Number. This is different from our current Laboratory Reference (prefix GrM-), which is a number assigned to an approved radiocarbon result. If an item is pretreated more than once using the same protocol, the same Sample Number is employed. If a different pretreatment method is applied, another Sample Number is issued which is linked to the original. The FileMaker Pro database contains records of all the electronic correspondence with the submitter; the pretreatment procedures applied to each sample; the resultant stable isotope and other supporting data. The current database and its historical predecessors can be interrogated for information on past analyses, including the samples pretreated for gas proportional counting, although details on some of the older records are stored on paper files only. An on-site archive is also maintained of excess unpretreated and pretreated sample material.

\section{Acceptance of Samples for Dating}

The CIO has always endeavored to ensure it does not inadvertently accept samples that were acquired illegally or unethically. Our protocols pertaining to this issue were recently revised and strengthened. In essence, requests for ${ }^{14} \mathrm{C}$ dates on artworks, craftworks or decorative objects, which are for commercial purposes only, will not be granted. Materials under strict international regulation, such as ivory, will also not be accepted unless the dates are being 
sought for the purposes of law enforcement or forensic research. For specific guidance on whether a sample may be submitted for dating, the reader is directed to the departmental website, given above.

\section{MAIN EQUIPMENT}

The CIO operates the following instruments and apparatus for ${ }^{14} \mathrm{C}$ dating and stable isotope measurements:

- $\quad$ MICADAS (Ionplus AG) $200 \mathrm{kV}$ accelerator mass spectrometer

- Gas Interface System (GIS, Ionplus AG) for direct ${ }^{14} \mathrm{CO}_{2}$ gas measurement on the MICADAS

- Carbonate Handling System (CHS, Ionplus AG) coupled to the GIS for carbonate evolution and direct measurement of gaseous ${ }^{14} \mathrm{CO}_{2}$ on the MICADAS

- Elemental analyzer (EA, Elementar Vario Isotope Select ${ }^{\mathrm{TM}}$ ) coupled to the GIS for combustion and direct ${ }^{14} \mathrm{CO}_{2}$ measurement on the MICADAS

- Tuneable infrared laser differential absorption spectrometer (Aerodyne Research) being optimized for high-precision determination of $\delta^{13} \mathrm{C}, \delta^{17} \mathrm{O}$ and $\delta^{18} \mathrm{O}$ in minute fractions of $\mathrm{CO}_{2}$

- A second EA (Elementar Vario Isotope Cube ${ }^{\mathrm{TM}}$ ) for combustion of solid and liquid samples

- Isotope Ratio Mass spectrometer (IRMS, IsoPrime $100^{\mathrm{TM}}$ ), coupled to the second EA, for routine $\delta^{13} \mathrm{C}$ and $\delta^{15} \mathrm{~N}$ measurement

- Automated cryogenic collection system (in-house), coupled to the second EA, for trapping the $\mathrm{CO}_{2}$ from combusted solid and liquid samples

- Five graphitization manifolds (in-house) each containing ten sample positions

- Automated graphite press (in-house)

- Combustion manifold (in-house) for the preparation of bulk $\mathrm{CO}_{2}$ standards (liters), such as the International Atomic Energy Agency (IAEA) C7, C8, OX-II and GS-51

\section{SAMPLE PREPARATION}

Solid materials are typically taken through pretreatment in batches of around 25 samples. A secondary standard is allocated to each batch and taken in parallel through pretreatment. The secondary standard is, where possible, of the same material type and approximately the same expected age. The stock of secondary standards at the CIO consists of both known-age materials and samples of greater than background age. Full pretreatment duplicates are also regularly implemented (see Quality Assurance, below).

\section{Physical Pretreatment}

Solid materials are commonly subjected to some form of physical preparation prior to chemical pretreatment. This usually involves eliminating extraneous soil and particulates from the bulk material by washing in ultrapure water, or careful scraping with a scalpel or metal brush. It is 
Table 1 Minimum and ideal starting weights (of dry material) for routine samples submitted to Groningen for ${ }^{14} \mathrm{C}$ dating. For minimumsized samples, submitters should liaise directly with the laboratory.

\begin{tabular}{lcc}
\hline & \multicolumn{2}{c}{ Starting weight $(\mathrm{mg})$} \\
\cline { 2 - 3 } Material type & Minimum & Ideal \\
\hline Bone & 100 & 1000 \\
Extracted collagen & 6 & 10 \\
Wood & 5 & 50 \\
Other plant remains & 5 & 50 \\
Charcoal, charred seeds, & 1 & 25 \\
$\quad$ and charred residues & 50 & 100 \\
Shell & 1000 & 4000 \\
Calcined bone & 10,000 & 10,000 \\
Soils and sediments & &
\end{tabular}

essential that exogenous plant material such as blades of grass, rootlets, or cotton/synthetic fibers from packaging are thoroughly removed before the item is sampled for dating.

Sampling is governed by the principle of utilizing the minimum amount of material necessary to obtain a successful date. In addition, it is designed to limit damage to characteristic or diagnostic features of both natural and cultural materials, and minimize the aesthetical impact on display pieces. Generally, portions of bone or wood are cut or drilled off using a clean saw or a Dremel $4000^{\mathrm{TM}}$. Large fragments may be crushed with percussion implements to expose greater surface area and enhance the effectiveness of the chemical pretreatment. Flimsy plant samples may also be removed with a scalpel or tweezers. Where possible, plant material is also cut or crushed into small fragments prior to chemical pretreatment. The amounts of starting material required by the $\mathrm{CIO}$ for routine ${ }^{14} \mathrm{C}$ dating are listed in Table 1. The smallest samples are often subject to bespoke treatments and, depending on preservation, are less likely to produce optimal dates. In general, the sample sizes described as ideal in Table 1 provide the best chance of obtaining a successful and precise result.

\section{Chemical Pretreatment}

The central goal of ${ }^{14} \mathrm{C}$ chemical pretreatment is to extract from the bulk sample an endogenous fraction that is likely to have remained chemically unmodified during deposition (de Vries and Barendsen 1954; van Klinken and Hedges 1998; Brock et al. 2010). This tends to be the comparatively inert structural biopolymers, such as collagen from bone and antler; keratin from fur, horn and nails; and cellulose from plant-based materials. For charcoal and charred seeds, the object is to extract the reduced carbon fraction. Non-polar organic compounds of either synthetic or natural origin such as oils, waxes and resins, glues and adhesives are generally not sought for dating because the material is likely to be either mobile in the environment or asynchronous with the date sought. For routine samples, such contamination usually relates to incidences of curatorial preservation or repair. Where glues or preservations are suspected on any solid sample, they are first subjected to an organic solvent pretreatment (see Dee et al. 2011; Brock et al. 2018). 


\section{Organic Solvent Pretreatment}

When required, the CIO implements a Soxhlet extraction procedure to eliminate additives such as glues and preservatives. This generally involves refluxing the sample for several hours in a series of organic solvents. The precise application is determined by the nature of the contaminant and guidance is sought from the relevant literature (Bruhn et al. 2001; Dee et al. 2011; Brock et al. 2018). Generally, the CIO employ the sequence suggested by Bruhn et al. (2001); namely, tetrahydrofuran, chloroform, petroleum ether, acetone and methanol. Routine solvent washes may also be conducted in test-tubes situated in dry-block heaters, with each solvent usually applied for at least $1 \mathrm{hr}$ at $45^{\circ} \mathrm{C}$. In all cases, it is essential that any organic (i.e. carboncontaining) solvent be allowed sufficient time, preferably at least $36 \mathrm{hr}$, to completely evaporate before proceeding to aqueous pretreatment.

\section{Aqueous Pretreatment}

The aqueous pretreatment procedures employed by Groningen are very similar to most other academic ${ }^{14} \mathrm{C}$ laboratories (e. g. Brock et al. 2010; Dunbar et al. 2016; Dumoulin et al. 2017; Steinhof et al. 2017). For human, animal and plant-based samples, the core is an acid-base-acid (ABA) procedure designed to eliminate geological carbonates, supramolecular humic substances from the soil, and any atmospheric $\mathrm{CO}_{2}$ absorbed during the alkaline phase. Each step is separated by at least a triplicate rinse with deionized and decarbonized water (referred to henceforth as DW).

The exact settings employed during aqueous pretreatment (i.e.: concentrations, temperatures, durations) are commonly modified to suit the sample in hand, utilizing the technical experience available at the laboratory. In general, treatments are made milder if the sample is either very small or very fragile. For the ABA steps, in order to minimize exposure to plastic surfaces, all reagents are prepared in glass flasks, and the samples are treated in glass vessels topped by watch-glasses. A general overview of the ABA steps employed at Groningen is given in Table 2.

\section{Wood, Seeds, and Uncharred Plant Remains}

The preparation of wood, most seeds, and uncharred material in the CIO laboratory is comparatively straightforward. The routine procedure follows the ABA scheme described in Table 2 with the first acid application conducted at $80^{\circ} \mathrm{C}$ and the second at room temperature. For specialist plant sample projects, non-routine pretreatments are applied, which include further chemical steps.

\section{Holocellulose Extraction (Non-Routine)}

If dating of the holocellulose fraction of wood, seeds or other uncharred plant remains is required, and sufficient sample material is available, the following steps are taken. Firstly, the routine ABA protocol is applied, as described above for wood, seeds and uncharred plant samples, but with both acid steps applied at $80^{\circ} \mathrm{C}$. Afterwards, an additional aqueous oxidation step (acidified $\mathrm{NaClO}_{2}, 80^{\circ} \mathrm{C}$ ) is employed as well as a final rinse to neutrality. Wood samples are generally robust enough for a $5 \%$ solution of acidified $\mathrm{NaClO}_{2}$ to be employed, but this reagent is weakened for some delicate materials such as paper or food remains. 
Table 2 The generic ABA protocol at Groningen. The exact temperatures and concentrations used are tailored to the nature of each sample.

\begin{tabular}{lcccccc}
\hline Step & Acid & Rinse & Base & Rinse & Acid & Rinse \\
\hline Reagent & $\mathrm{HCl}$ & $\mathrm{DW}(3 \mathrm{x})$ & $\mathrm{NaOH}$ & $\mathrm{DW}(3 \mathrm{x})$ & $\mathrm{HCl}$ & $\mathrm{DW}(3 \mathrm{x})$ \\
Conc (w/vol) & $4 \%$ & - & $1 \%$ & - & $4 \%$ & - \\
Time (min) & $>30$ & - & $>30$ & - & $\sim 30$ & - \\
Temp $\left({ }^{\circ} \mathrm{C}\right)$ & $\mathrm{RT}-80$ & $\mathrm{RT}$ & $\mathrm{RT}-80$ & $\mathrm{RT}$ & $\mathrm{RT}-80$ & $\mathrm{RT}$ \\
\hline
\end{tabular}

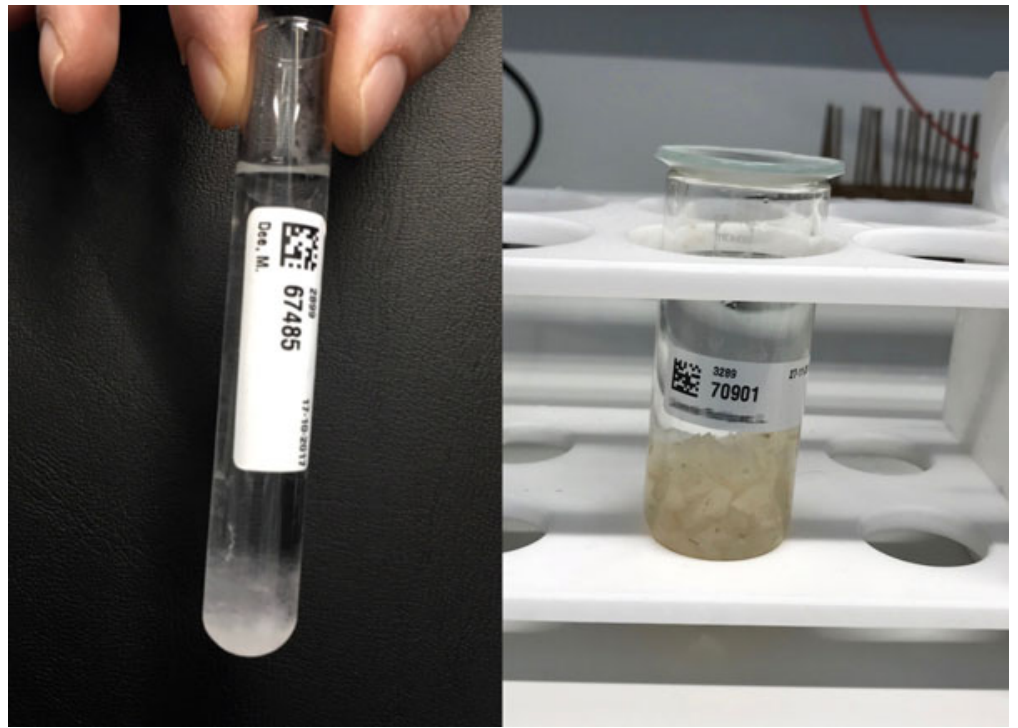

Figure 2 Images of an alpha-cellulose pretreatment in progress (left) and collagen being demineralized in weak acid in a glass centrifuge vessel topped by a watch glass (right).

\section{$\alpha$-Cellulose Extraction (Non-Routine)}

For projects requiring especially high precision, such as tree-rings for calibration or cosmic ray studies (see Hua et al. 1999; Hogg et al. 2006; Dee et al. 2017), the CIO now also applies an $\alpha$-cellulose wood pretreatment. The method draws strongly on the work of Hoper et al. (1998); Hogg et al. (2006, 2013) and Staff et al. (2014). It also follows the same general steps of a physical preparation, optional organic solvent rinse, and an intensified aqueous pretreatment protocol (Figure 2). The reliability of our $\alpha$-cellulose method is demonstrated in Figure 3. Thus far, 33 different single-year samples have been pretreated in duplicate and 31 results passed the Ward and Wilson (1978) test for statistical consistency (see Figure 3).

\section{a. Physical Pretreatment}

Any extraneous material is removed using compressed air, or by shaving off the outermost surface with a razor blade. For single tree-ring analysis, rings are cleaved using a scalpel or stainless steel blade. The wood fragments are then further cut into as small pieces as possible, to enhance the effectiveness of the pretreatment. If the wood is too dense to be 


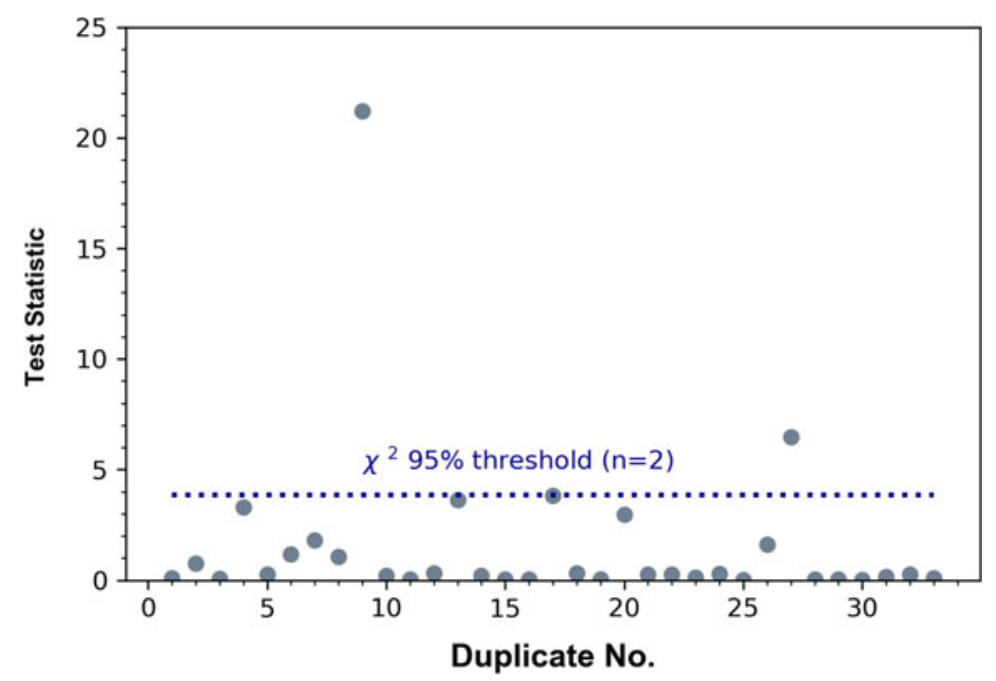

Figure 3 Duplicated pretreatments on dendrochronological tree-rings using the CIO's new $\alpha$-cellulose method. By calculating the test statistic $\left(\chi^{2}\right.$ distribution, $\mathrm{n}-1$ degrees of freedom, see Ward and Wilson 1978) the congruence of pairs of results can be assessed. If the t-statistic for each pair is lower than the threshold for statistical consistency $(3.84,95 \%$ probability), the two results can be considered indistinguishable. Here, only 2 of the 33 results failed to meet this criterion.

cut with a blade, rings may be ground off using an automatic milling device such as a Dremel 4000. Normally, $50 \mathrm{mg}$ of starting material is sufficient.

\section{b. Organic Solvent Pretreatment}

Organic solvent washes are only applied if the tree species is known to be resinous and the risk of the colocation of carbon-containing material is high. Such species include pine, kauri, cedar and sequoia, but exclude oak. The taphonomy of the sample is also taken into consideration. For example, in the case of driftwood, an organic solvent rinse may be considered superfluous. Generally, due to the numbers of samples requiring preparation, it is not practical to employ Soxhlet apparatus, so the samples are placed in test-tubes in a dry-block heater (Fisher Scientific). In any event, recent studies suggest there is no net gain from applying the former method over the latter (MacDonald et al. 2019). The routine sequence applied at Groningen is as follows: acetone $\left(45^{\circ} \mathrm{C}, 6 \mathrm{hr}\right)$; dry thoroughly $(>36 \mathrm{hr})$; DW $\left(45^{\circ} \mathrm{C}, 6 \mathrm{hr}\right)$; dry overnight.

\section{c. Intensified Aqueous Pretreatment}

The aqueous pretreatment commences with a strong acid $\left(\mathrm{HCl}, 5.47 \% \mathrm{w} / \mathrm{vol}(1.5 \mathrm{M}), 80^{\circ} \mathrm{C}\right.$, $20 \mathrm{~min})$, followed by triplicate rinses with DW. Then a strong base $(\mathrm{NaOH}, 17.5 \% \mathrm{w} / \mathrm{vol}$, $60 \mathrm{~min}, \mathrm{RT}$ ) is applied, during which the reaction vessels are ultrasonicated under a $\mathrm{N}_{2}$ atmosphere. The supernatant fluid is then decanted off and the samples rinsed five times with DW, before strong acid is applied once more $\left(\mathrm{HCl}, 5.47 \% \mathrm{w} / \mathrm{vol}, 80^{\circ} \mathrm{C}, 20 \mathrm{~min}\right)$. Once a further triplicate rinse has been conducted, the next step involves an aqueous oxidation phase in a dry-block heater $\left(\mathrm{NaClO}_{2}, 1.5 \%\right.$ w/vol in $\left.\mathrm{HCl}(0.06 \mathrm{M}), 80^{\circ} \mathrm{C}\right)$. The samples are left for $16 \mathrm{hr}$, and then a freshly prepared solution in the acidified oxidant is applied for a further $4 \mathrm{hr}$. Finally, the samples are rinsed 3 times, frozen and freeze-dried (Edwards Modulyo $\left.{ }^{\mathrm{TM}}\right)$. 


\section{Charcoal, Charred Seeds, and Charred Residues}

The preparation of charred plant material is comparatively straightforward. The routine procedure follows the scheme described in Table 2 and has differed little at the CIO since its original development for gas proportional counting by Mook and Streurman (1983). Where only small amounts of starting material are available $(<10 \mathrm{mg})$, it may be deemed permissible for some locations to subject the sample to an acid-only rinse. This course-ofaction assumes the humic substances present are contemporary with the reduced carbon fraction. However, this approach is generally only employed for arid environments, such as certain sites in the ancient Near East, where there is considerable evidence the assumption is valid (Wild et al. 2013).

\section{Bone}

Two types of pretreatment are applied to bone samples. By far the most common is collagen extraction from whole bone via a modified Longin protocol (Longin 1971; Mook and Streurman 1983). The second is acid digestion of the inorganic (apatite) fraction. The latter method, pioneered at the CIO (Lanting and Brindley 1998; Lanting et al. 2001), is generally only employed for bones that have been calcined as a result of cremation. Partially charred or burnt bone is generally not suitable for ${ }^{14} \mathrm{C}$ dating (Zazzo and Saliège 2011).

\section{a. Collagen}

To extract the collagen fraction from bone samples, fragments are first subject to a mild ABA pretreatment. Powdered bone samples are not suitable for the routine method applied at the CIO. Our method lies between the "chunks" and "gelatinization and ultrafiltration" dichotomy discussed by Sealy et al. (2014). The bone samples are first decalcified over at least a 24-hr period using mild acid $(\mathrm{HCl}, 2-4 \% \mathrm{w} / \mathrm{vol}, \mathrm{RT})$. If the material is not soft, the acid solution is refreshed and soft portions removed and stored separately in DW until further preparation. When the solution has stopped bubbling and all the fragments have become soft and pliable, they are rinsed thoroughly with DW. Subsequently, the extract is exposed to $\mathrm{NaOH}(1 \%, \sim 30 \mathrm{~min})$ to eliminate humic acids, rinsed to neutrality, treated again with acid $(\mathrm{HCl}, 4 \% \mathrm{w} / \mathrm{vol}, 15 \mathrm{~min})$ and then rinsed once more to neutrality. The raw collagen fraction is then denatured to gelatin in acidified $\mathrm{DW}(\mathrm{pH} \mathrm{3})$ at $80^{\circ} \mathrm{C}$ for $18 \mathrm{hr}$. The dissolved gelatin is then filtered through a $50 \mu \mathrm{m}$ mesh to eliminate any remaining foreign particulates and thoroughly dried. Finally, the crystalline product is scraped from sides of the glass vessels for weighing out.

\section{b. Calcined Bone}

The calcination of bone, from processes such as cremation, results in a closed system frequently making the inorganic fraction reliable for dating (Lanting and Brindley 1998; Zazzo and Saliège 2011). At the CIO, calcined bone is first subjected to a weak oxidation $(1.5 \% \mathrm{w} / \mathrm{vol}$, $\left.\mathrm{NaClO}_{2}\right)$ to remove any organic material $(48 \mathrm{hr}, \mathrm{RT})$. Afterwards, it is rinsed with DW to neutral $\mathrm{pH}$, and a weak acid applied to eliminate the adsorbed carbonate ions that are most likely to have exchanged with the environment $\left(\mathrm{CH}_{3} \mathrm{COOH}, 6 \% \mathrm{w} / \mathrm{vol}(1 \mathrm{M}), 24 \mathrm{hr}\right.$, RT). The cleaned apatite fraction is then rinsed again, dried overnight at $85^{\circ} \mathrm{C}$, and crushed into small pieces. An aliquot $(\sim 2 \mathrm{~g})$ of the crushed product is placed in one arm of a Y-shaped glass reaction vessel. A saturated acid solution $\left(\mathrm{H}_{3} \mathrm{PO}_{4}\right)$ is pipetted into the second arm, and the vessel evacuated on a custom-built vacuum manifold. The acid is then mixed with the calcined bone fragments and the vessels placed in a water bath $\left(25^{\circ} \mathrm{C}, 24 \mathrm{hr}\right)$. 
The $\mathrm{CO}_{2}$ evolved over this time is cryogenically transferred to a glass flask containing about 15 Sulfix ${ }^{\mathrm{TM}}$ particles (WAKO, 8 20 mesh, mixture of $\mathrm{Co}_{3} \mathrm{O}_{4}$ and $\mathrm{Ag}_{2} \mathrm{O}$ ) and stored for $18 \mathrm{hr}$ in a heat block $\left(200^{\circ} \mathrm{C}\right)$, to remove sulphurous components. The Sulfix is preheated in oxygen ( $\sim 200^{\circ} \mathrm{C} \mathrm{C}$, overnight) to ensure its purity before each use. Furthermore, the CIO is currently exploring alternative approaches, which would allow Sulfix to be excluded altogether.

\section{Shell}

Like calcined bone, the carbonate fraction of shell can reliably be dated by dissolution to $\mathrm{CO}_{2}$. Shells are first etched with acid $(\mathrm{HCl}, 4 \%)$ to remove the outermost surface, rinsed with DW, dried and crushed to powder. The subsequent acid digestion step is similar to that applied to calcined bone. An aliquot ( $20 \mathrm{mg}$ ) of the crushed shell is placed in one arm of Y-shaped glass reaction vessel. A saturated acid solution $\left(\mathrm{H}_{3} \mathrm{PO}_{4}\right)$ is pipetted into the second arm, and the vessel evacuated on a vacuum line. The acid is then tipped onto the shell fragments and the glass vessels placed in a water bath $\left(25^{\circ} \mathrm{C}, 24 \mathrm{hr}\right)$. The $\mathrm{CO}_{2}$ evolved over this period is cryogenically transferred into a glass flask for stable isotope $\left(\delta^{18} \mathrm{O}\right.$ and $\left.\delta^{13} \mathrm{C}\right)$ analysis and subsequent graphitization and ${ }^{14} \mathrm{C}$ measurement.

\section{Soils and Sediments}

Soil samples are rarely suitable for high-precision ${ }^{14} \mathrm{C}$ dating. The main difficulty lies in determining whether the organic fractions obtained come from specific strata in the soil, or from more mobile phases. Nonetheless, in certain circumstances, "bulk" samples from lake sediments or peat bogs may provide useful age estimates. Here, the CIO employ the rudimentary protocol outlined in Table 2 , with the reagents usually kept at $80^{\circ} \mathrm{C}$. It is preferable to identify specific plant remains (except roots), but if only amorphous organic material is present in particulate form then both the base soluble (humic) and acid and base insoluble (humin) fractions are kept, dried and dated, to provide additional information on the integrity of the soil profile.

\section{Combustion and Graphitization}

Aliquots of the pretreatment products are weighed into tin capsules for combustion. The precise quantity weighed out depends on expected carbon content, and thus differs for each sample type. The capsules are combusted in an EA coupled to an IRMS and an automated cryogenic collection system. The IRMS allows $\delta^{13} \mathrm{C}( \pm 0.15 \%$, VPDB $)$ and $\delta^{15} \mathrm{~N}( \pm 0.30 \%$, Air $)$ values to be determined for all samples submitted for ${ }^{14} \mathrm{C}$ dating. The cryogenic system traps the $\mathrm{CO}_{2}$ released into sealable glass vessels. When the combustion run is complete, the glass vessels are transferred to one of five graphitization manifolds, each of which can take a maximum of ten samples (Aerts-Bijma et al. 2001). Four manifolds are used for regular-sized samples $(>0.5 \mathrm{mg} \mathrm{C}$ ), and the other is a bespoke rig for small samples. Each graphitization position on the manifolds is isolatable and has a $\mathrm{T}$ shape, so one "finger" can be cooled whilst the other, a detachable tube, is heated. Prior to use, the detachable tube is loaded with an Fe powder catalyst $(\sim 2 \mathrm{mg})$, except in the case of small sample preparations, where an Fe pellet is used ( 1.5 mg, de Rooij et al. 2010). The whole manifold is first evacuated, and each reaction position isolated. The $\mathrm{CO}_{2}$ from each sample is then introduced, and a stoichiometric excess of $\mathrm{H}_{2}$ gas (1: 2.5) added. The hot tube is placed in an oven at $600^{\circ} \mathrm{C}$ and the cold finger, which draws water vapor from the 
reaction site, is chilled to between -15 and $-20^{\circ} \mathrm{C}$ using a Peltier device. As the reaction proceeds, graphite forms on the catalyst. Pressure transducers follow the course of the reaction to ensure it proceeds to completion.

\section{Pretreatment Quality Assurance}

The CIO employs multiple safeguards for quality control purposes. A secondary (background or known-age) standard is included with each pretreatment batch and taken in parallel through the whole process. Obtaining the correct result for these materials substantiates the ages obtained for the unknown samples. The pretreatment standards we currently utilize include:

- Horse bone (Holocene, VIRI intercomparison, Scott et al. 2010)

- Owen Buddleia charcoal (Modern, Oxford Radiocarbon Accelerator Unit)

- Charred seeds from Jericho (Holocene, in-house)

- Dendrochronological tree-rings (Holocene and modern, Dutch Cultural Heritage Agency, Amersfoort, Historic England, London)

- Charcoal (Background, Christian-Albrechts-Universitat, Kiel)

- Mammoth and rhino bones (Background, in-house)

- Carbonate (Local background material, GS-35)

Furthermore, one sample in each batch is split and pretreated in duplicate. This protocol ensures the results are reproducible, irrespective of the sample's age or depositional history.

In addition to procedural standards, the CIO also employs rejection criteria based on the data acquired during pretreatment. This helps ensure the purity of the pretreatment product, and hence the accuracy of the resultant date. Most yields of less than $0.5 \mathrm{mg}$ or $0.5 \%$ (relative to starting weight) are automatically rejected. Collagen samples are failed outright if the C:N ratio on combustion is not between 2.9-3.6. A warning is issued with the ${ }^{14} \mathrm{C}$ result if the $\mathrm{C}: \mathrm{N}$ ratio is not between $3.1-3.3$. Where such cases occur, the cause of the contamination and whether or not it can be remedied is always investigated. For carbonate samples, another key criterion is whether non-condensable gases are observed during the extraction process.

Finally, the CIO also employs many other standards for the purposes of ensuring the accuracy of the laboratory's IRMS measurements. Data on such references will be reported and assessed in forthcoming complementary articles.

\section{CONCLUSIONS}

The last major overview of the chemical pretreatment procedures for ${ }^{14} \mathrm{C}$ dating employed by the CIO was Mook and Streurman (1983). Whilst several procedures have remained unchanged since that time, others have been modified, and new ones have been added to the repertoire. This article brings reporting up to date on all of the chemical procedures and processes employed by the ${ }^{14} \mathrm{C}$ dating facility.

\section{ACKNOWLEDGMENTS}

M. W. Dee, M. Kuitems, and A. Scifo are supported by a European Research Council Grant (714679, ECHOES). 


\section{REFERENCES}

Aerts-Bijma AT, Meijer H, van der Plicht J. 1997. AMS sample handling in Groningen. Nuclear Instruments and Methods in Physics Research B 123(1-4): 221-225. doi: 10.1016/S0168-583X(96)00672-6.

Aerts-Bijma AT, van der Plicht J, Meijer H. 2001. Automatic AMS sample combustion and $\mathrm{CO} 2$ collection. Radiocarbon 43(2A):293-298. doi: 10.1017/S0033822200038133

Brock F, Higham TFG, Ditchfield P, Bronk Ramsey C. 2010. Current pretreatment methods for AMS radiocarbon dating at the Oxford Radiocarbon Accelerator Unit (ORAU). Radiocarbon 52(1):103-112. doi: 10.1017/S0033822200045069.

Brock F, Dee M, Hughes A, Snoeck C, Staff R, Bronk Ramsey C. 2018. Testing the effectiveness of protocols for removal of common conservation treatments for radiocarbon dating. Radiocarbon 60(1):35-50. doi: 10.1017/RDC.2017.68.

Bruhn F, Duhr A, Grootes PM, Mintrop A, Nadeau M-J. 2001. Chemical removal of conservation substances by 'Soxhlet'-type extraction. Radiocarbon 43(2A):229-237. doi: $10.1017 /$ S0033822200038054.

Dee MW, Brock F, Bowles AD, Bronk Ramsey C. 2011. Using a silica substrate to monitor the effectiveness of radiocarbon pretreatment. Radiocarbon 53(4):705-711. doi:10.1017/S0033822200039151.

Dee MW, Pope B, Miles D, Manning S, Miyake F. 2017. Supernovae and single-year anomalies in the atmospheric radiocarbon record. Radiocarbon 59(2):293-302. doi:10.1017/RDC.2016.50.

de Vries HI, Barendsen GW. 1952. A new technique for the measurement of age by radiocarbon. Physica 18:652.

de Vries Hl, Barendsen GW. 1953. Radiocarbon dating by a proportional counter filled with carbon dioxide. Physica 19:987-1003.

de Vries Hl, Barendsen GW. 1954. Measurements of age by the carbon-14 technique. Nature 174(4442): 1138-1141.

Dumoulin J-P, Comby-Zerbino C, Delqué-Količ E, Moreau C, Caffy I, Hain S, Perron M, Thellier B, Setti V, Berthier B, Beck L. 2017. Status report on sample preparation protocols developed at the LMC14 laboratory, Saclay, France: from sample collection to ${ }^{14} \mathrm{C}$ AMS measurement. Radiocarbon 59(3):713-726. doi: 10.1017/RDC.2016.116.

Dunbar E, Cook GT, Naysmith P, Tripney BG, Xu S. 2016. AMS ${ }^{14} \mathrm{C}$ dating at the Scottish Universities Environmental Research Centre (SUERC) radiocarbon dating laboratory. Radiocarbon 58(1):9-23. doi:10.1017/RDC.2015.2.

Dusek U, Monaco M, Prokopiou M, Gongriep F, Hitzenberger R, Meijer HA, Rockmann T. 2014. Evaluation of a two-step thermal method for separating organic and elemental carbon for radiocarbon analysis Atmospheric Measurement
Techniques 7:1943-1955. doi: 10.5194/amt-7-19432014

Hogg AG, Fifield LK, Turney CSM, Palmer JG, Galbraith R, Baillie M. 2006. Dating ancient wood by high-sensitivity liquid scintillation counting and accelerator mass spectrometrypushing the boundaries. Quaternary Geochronology 1(4): 241-8. doi: 10.1016/j.quageo.2006.11.001.

Hogg A, Turney C, Palmer J, Southon J, Kromer B, Bronk Ramsey C, Noronha A, Staff RA, Fenwick P, Boswijk G, Friedrich M, Reynard L, Guetter D, Wacker L, Jones R. 2013. The New Zealand Kauri (Agathis australis) Research Project: a radiocarbon dating intercomparison of Younger Dryas wood and implications for IntCal13. Radiocarbon 55(4):2035-2048. doi: 10.2458/ azu_js_rc.v55i2.16217.

Hua Q, Barbetti M, Worbes M, Head J, Levchenko V. 1999. Review of radiocarbon data from atmospheric and tree ring samples for the period 1945-1997 AD. IAWA Journal 20(3): 261-283. doi: 10.1163/ 22941932-90000690.

Hoper ST, McCormac FG, Hogg AG, Higham TFG, Head MJ. 1998. Evaluation of wood pretreatments on oak and cedar. Radiocarbon 40(1):45-50. doi: 10.1017/S0033822200017860.

Lanting JN, Aerts-Bijma, AT, van der Plicht J. 2001. Dating of cremated bone. Radiocarbon 43(2A): 249-254. doi: 10.1017/S0033822200038078.

Lanting JN, Brindley AL. 1998. Dating cremated bone: the dawn of a new era. Journal of Irish Archaeology 9:1-7.

Longin R. 1971. New method of collagen extraction for radiocarbon dating. Nature 230(5291):241-242.

MacDonald L, Chivall C, Miles D, Bronk Ramsey C. 2019. Seasonality in tree ring calibration data: implications for curve construction and calibration. Radiocarbon 61(1):185-194. doi: 10.1017/RDC. 2018.64

Mook WG, Streurman HJ. 1983. Physical and chemical aspects of radiocarbon dating. PACT 8(II):45-53.

Palstra SWL, Meijer HAJ. 2014. Biogenic carbon fraction of biogas and natural gas fuel mixtures determined with ${ }^{14} \mathrm{C}$. Radiocarbon 56(1):7-28. doi: $10.2458 / 56.16514$

de Rooij M, van der Plicht J, Meijer HAJ. 2010. Porous iron pellets for AMS C-14 analysis of small samples down to ultra-microscale size (10-25 mu gC). Nuclear Instruments and Methods in Physics Research B 268(7-8):947-951. doi: 10.1016/j. nimb.2009.10.071

Scott EM, Cook GT, Naysmith P. 2010. A report on phase 2 of the Fifth International Radiocarbon Intercomparison (VIRI). Radiocarbon 52(2-3):846-858. doi: 10.1017/S00338 22200045938. 
Sealy J, Johnson M, Richards M, Nehlich O. 2014. Comparison of two methods of extracting bone collagen for stable carbon and nitrogen isotope analysis: comparing whole bone demineralization with gelatinization and ultrafiltration. Journal of Archaeological Science 47:64-69. doi: 10.1016/j. jas.2014.04.011

Staff RA, Reynard L, Brock F, Bronk Ramsey C. 2014. Wood pretreatment protocols and measurement of tree-ring standards at the Oxford Radiocarbon Accelerator Unit (ORAU). Radiocarbon 56(2): 709-715. doi: 10.2458/56.17449.

Steinhof A, Altenburg M, Machts H. 2017. Sample preparation at the Jena ${ }^{14} \mathrm{C}$ laboratory. Radiocarbon 59(3):815-830. doi: 10.1017/RDC. 2017.50.

Stuiver M, Polach HA. 1977 Radiocarbon 19(3):355-363. doi: 10.1017/S003382220000 $3672 \mathrm{P}$. van Klinken GJ, Hedges REM. 1998. Chemistry strategies for organic ${ }^{14} \mathrm{C}$ samples. Radiocarbon 40(1):51-56. doi: 10.1017/S0033822200017872.

Ward GK, Wilson SR. 1978. Procedures for comparing and combining radiocarbon age determinations: a critique. Archaeometry 20(1):19-31.

Wijma S, Aerts AT, van der Plicht J, Zondervan A. 1996. The Groningen AMS facility. Nuclear Instruments and Methods in Physics Research B 113:465-469. doi: 10.1016/0168-583X(95)01420-9.

Wild EM, Steier P, Fischer P, Höflmayer F. $2013 .{ }^{14} \mathrm{C}$ dating of humic acids from Bronze and Iron Age plant remains from the Eastern Mediterranean. Radiocarbon 55(2-3):599-607. doi: 10.2458/ azu_js_rc. 55.16450 .

Zazzo, A, Saliège JF. 2011. Radiocarbon dating of biological apatites: A review. Palaeogeography, Palaeoclimatology, Palaeoecology 310:52-61. doi: 10.1016/j.palaeo.2010.12.004. 